\title{
GUT MICROBIOTA AND HEALTH: A REVIEW WITH FOCUS ON METABOLIC AND IMMUNOLOGICAL DISORDERS AND MICROBIAL REMEDIATION
}

\author{
Biswaranjan Pradhan', David Datzkiw ${ }^{2}$, and Palok Aich ${ }^{\mathbf{1}}$ \\ ${ }^{1}$ National Institute of Science Education and Research Bhubaneswar (HBNI), School of Biological \\ Sciences, Jatani, Khurdha, Odisha, India, and ${ }^{2}$ Department of Biology, University of Winnipeg, \\ Winnipeg, Manitoba, Canada R3B 2 G3
}

Understanding and defining health is an important yet fuzzy topic. Despite several attempts, health is not a well-defined concept, therefore we seek to understand health from the perspective of the microbiome. Gut microbiota are an essential component in the modern concept of human health. However, the precise patterns of composition and functional characteristics of a healthy gut microbiome remain ill-defined. Microbial colonization patterns associated with disease states have been documented with the advancement of sequencing technologies. Several prebiotics and probiotics have been reported to restore the normal gut flora after being disrupted by various factors. Fecal microbial transplantation from healthy individuals into recipients suffering from diseases related to gut dysbiosis has also been reported to be effective in restoring the normal makeup of gut microbiota, as shown by its efficacy in treating Clostridium difficile infection, colitis, constipation, irritable bowel syndrome, and neurological conditions such as multiple sclerosis and Parkinson's disease. In this review we attempt to define the parameters of healthy human gut flora and its disruption in diseased conditions, and restoration through administration of prebiotics, probiotics, and fecal microbial transplantation. Biomed Rev 2016; 27: 1-17.

Key words: microbiota, microbiome, metabolism, autoimmunity, probiotics, fecal microbial transplantation, disease

\section{INTRODUCTION}

The meaning of the word health is highly ambiguous and subjective to the user, context, and social setting. Health is usually in reference to either physical or mental health, however, the matter becomes complicated when attempting to establish fixed set of parameters that can be used to define and predict health quantitatively. To date, the best known modern definition for health was put forth during the creation of the Constitution of the World Health Organization (WHO) (1) and entered into force on 7 April 1948. It broadly states that health is "a state of complete physical, mental, and social well-being and not merely the absence of disease or infirmity". However, many question the suitability of this definition in an era now marked by leaps in the understanding disease at the molecular, individual, and societal levels (2).

A significant obstacle to improving the definition of health

Received 17 November 2016, revised 8 December 2016, accepted 11 December 2016.

Correspondence to Dr Palok Aich, School of Biological Sciences PO: Bhimpur-Padanpur,

Pin-752050, Jatani, Khurdha, Odisha, India. Phone: +91-674-2494133, Fax:+916742494004, E-mail: palok.aich@niser.ac.in 
comes from that fact that "health" is a social construct, widely open to interpretation, and ever changing throughout our natural lives. For instance, a physically fit athlete at the age of 25 , an individual living with Down syndrome, and an elderly person at the age of 85 could all be considered "healthy", yet differ immensely in terms of physical and mental capabilities. Where do we draw the line between healthy passion and unhealthy obsessive or addictive behaviour? Furthermore, paradoxically an individual could be considered physically fit and "healthy", yet be considered mentally "unhealthy", and vice versa, at the same time. The relative nature of health is made more complex when individual or cultural perception is taken into account. This is readily apparent in the disparity of how individuals, from different cultural backgrounds, view obesity, a disease well-established by the scientific community to confer a myriad of negative physiological effects (3). For example, non-Hispanic white women experience greater social pressure to be thin than African American women (4) with the latter expressing satisfaction with their body image and health at higher mean body mass index (BMI) than that of the former (5).

\section{Abbreviations used}

AAD, antibiotic-associated diarrhea

AMPK, adenosine monophosphate-activated protein kinase

BMI, body mass index

CAC, colitis associated cancer

$\mathrm{CD}$, Crohn's disease

CDI, Clostridium difficile infection

$\mathrm{CRC}$, colorectal cancer

ETBF, enterotoxigenic Bacteroides fragilis

FIAF, fasting-induced adipose factor

FMT, fecal microbial transplantation

GLP-1, glucagon-like peptide 1

HGC, high gene count

IBD, inflammatory bowel disease

IBS, irritable bowel syndrome

IL, interleukin

LGC, low gene count

NOD, non-obese diabetic

OAMD, obesity associated metabolic disorders

OTUs, operational taxonomic units

PKS, polyketide synthase

UC, ulcerative colitis

WHO, World Health Organization
Gray areas will always exist within the concept of health; however, there is ample room to expand our understanding of health by establishing more concrete and predictable parameters at a molecular and cellular level. Deep understanding of our cellular and molecular selves and the underlying mechanisms and systems at hand are very much needed, not only to define health, but also to manipulate and regulate it. In general, a species is defined by its genome and epigenome, but for various organisms including humans, these two concepts alone are not adequate. Another component of the human body is its microbiome, the collective gene functions of all microorganisms inhabiting various sites of the human body. In particular, the human gut is home to an enormous number of microorganisms, approximately 100 trillion bacteria cells, outnumbering human cells by an estimated 10 fold (6). The changes in gut microbial composition have been associated with many infectious and metabolic disorders (Table 1). Identifying the patterns of both healthy gut flora and the gut flora of multiple states of disease will provide another crucial facet in defining the parameters of health, and will help develop methods to maintain or return to a state of desired health. The important terms and their meanings are listed in Box 1.

The gut metagenome (complete set of microbial genes) is 150 times greater than the human genome (7). The adult-like population of microbiota forms at around age 3 (8), shifting from a microbiome that primarily plays a role in lactate digestion, to a more stable population that aids in polysaccharide hydrolysis, vitamin biosynthesis and xenobiotic degradation (9). The gut microbiota consists of a diverse variety of species, including organisms such as bacteria, archaea, eukarya, viruses and endoparasites $(10,11)$. The healthy human gut is also inhabited by a few select fungal organisms, including different Candida yeasts and yeast belonging to the family Dipodascaceae (Galactomyces, Geotrichum, Saprochaete) (12). The approximate composition of the gut microbiota is $92.9 \%$ bacteria, $0.5 \%$ eukaryotes, $0.8 \%$ archaea and $5.8 \%$ viruses (13). Approximately, 1000 bacterial species inhabit the human gut (7). Bacteroidetes and Firmicutes are the most abundant phyla in the human gut $(6,14)$. Bacteroides are the most abundant and also the most variable genus between different samples (13). Bacterial species richness is higher in healthy individuals and lower in people of poor health, or those with low-grade chronic inflammation $(15,16)$. Microbial ecosystems that are higher in species richness are more resistant to perturbation from the outside environment (17). Competitive exclusion may prevent a growth bloom in 
pathogenic bacteria (18); competitive interactions between species may also help in stabilizing the gut microbiome (19). Gut microbial composition varies significantly in diseased individuals than that of healthy populations. Differential composition of gut microbiota in individuals suffering from illness is correlated with specific metabolic and immunological disorders. In the first part of this review, we discuss the differential composition of gut microbiota in obese, diabetic, Clostridium difficile infection (CDI), irritable bowel syndrome (IBS), inflammatory bowel disease (IBD) patients with respect to healthy samples. Although we have restricted the scope of our study to diseases related to digestion and metabolism, it should be noted that dysbiosis is pleiotropic, with the capability of driving neurological diseases such as multiple sclerosis and Parkinson's disease $(20,21)$. Recent developments in gut microbial remediation through prebiotics, probiotics and fecal microbial transplantation (FMT) are reviewed in the latter part of this article

\section{MICROBIAL-LINKED METABOLIC DISORDERS}

\section{Obesity and gut microbiota}

The prevalence of obesity has doubled globally from 1980 to 2014 , with there now being over 600 million obese individuals as estimated by the WHO $(22,23)$. The known factors contributing to obesity are numerous, including environmental circumstances, life style and diet habits, and genetics (24). Among environmental factors, geography is also thought to highly influence an individual's susceptibility to obesity. This was demonstrated through Kaufman's large scale study comparing obesity and health of black populations in the United States and Caribbean, of African origin, to black populations currently residing in Nigeria and Cameroon. Obesity rates are significantly higher in developed nations (23). Geographical or genetic differences cannot alone explain the sudden increase in obesity rates worldwide. The more plausible explanation for this shift is due to changes in diet and physical activity patterns, which have the potential to alter the gut microbiota $(25,26)$; this notion is well supported by emerging evidence that has shown both correlative changes in microbiota associated with obesity, and direct causative effects by microbiota that contribute to obesity $(17,27-30)$. Suzuki et al demonstrated the correlation between increased Firmicutes and regions with cold weather, colder climates being associated with higher body mass (Bergmann's rule) (31); a higher ratio of Firmicute bacteria compared to Bacteroides is associated with obesity (28). Following bacterial colonization of germ-free mice, body fat content significantly increases, marked by increased lipoprotein lipase mediated triglyceride storage after microbe mediated inhibition of expression of fasting-induced adipose factor (FIAF) in the intestines (29). It was demonstrated by Backhed et al that the gut microbiota are able to induce adipose tissue accumulation through inhibition of phosphorylated adenosine monophosphate-activated protein kinase (AMPK)-dependent fatty acid oxidation, as observed by p-AMPK and acetylCoA carboxylase (Acc) expression levels, as well as carnitine-palmityoyl transferase-1 activity, which were all down-regulated in germ free mice following microbial colonization of the gut (32). Le Chatelier et al tried to categorise obese people according to the composition of their gut microbiota. They found a bimodal distribution of microbial gene richness in obese individuals, stratifying individuals as high gene count (HGC) or low gene count (LGC) (33). Individuals with HGC were characterised by higher prevalence of presumed anti-inflammatory species such as $F$. prausnitzii, and an increased production potential of short chain organic acids. In contrast, LGC individuals showed higher relative abundance of potentially pro-inflammatory Bacteroides species and genes involved in oxidative stress response (33). Diet-induced weight-loss intervention significantly increased gene richness in the LGC individuals, which was associated with improved metabolic status (34). These findings support the reported link between long-term dietary habits and the structure of the gut microbiota. It also suggests permanent adjustment of the microbiota may be achieved through diet modification. A causal relationship was established between host glucose homoeostasis and gut microbial composition. Fecal microbial transplantation from lean donors to individuals with metabolic syndrome significantly increased insulin sensitivity in the latter (35). The transplant produced an increase in faecal butyrate concentrations, microbial diversity, and the relative abundance of bacteria related to the butyrate-producing Roseburia intestinalis (35). Together, these studies produce a body of evidence that the microbiome plays a role in host energy homoeostasis, and the establishment and development of obesity associated metabolic disorders (OAMD). The gut of individuals with OAMD is believed to harbour an inflammation-associated microbiome, with a lower potential for butyrate production and reduced bacterial diversity and/or gene richness. Differences in gut microbial ecology might be an important mediator and a new therapeutic target or a biomarker to predict metabolic dysfunction/obesity in later life. 


\section{Box 1. Important terms}

\section{Microbiota}

The types of microorganisms that are present in a habitat; including bacteria, viruses and eukaryotes.

\section{Microbiome}

A collection of different microbes found in a given habitat and their collective gene functions. For example, skin microbiome, gut microbiome etc.

\section{Metagenomics}

A method which allows us to create catalogues of what the microbiome can do as a single unit based on the collective genes they have.

\section{Dysbiosis}

A disturbance or imbalance in a biological system, for example, changes in the types and numbers of bacteria in the gut which may lead to developing different diseases, such as inflammatory bowel disease.

\section{Pathobiont}

A commensal organism that can cause disease when specific genetic or environmental conditions are altered in the host.

\section{Prebiotics}

A selectively fermented ingredient that results in specific changes in the composition and/or activity of the gut microbiota, thus conferring benefits upon host health.

\section{Probiotics}

Live microorganisms that, when administered in adequate amounts, confer a health benefit on the host. Examples include strains of the genera Bifid bacterium and Lactobacillus.

\section{Fecal microbial transplantation}

The introduction of gut bacteria from a healthy donor into a patient, through transfer of an infusion of a fecal sample via administration through nasal, oral, or rectal tubes.

\section{Diabetes and the gut microbiota}

Individuals that have developed type 2 diabetes mellitus or some degree of glucose intolerance, consistently exhibit altered populations of gut microbiota, with certain key species either enriched or supressed (36). A clinical study of diabetic adult males revealed that the proportions of class Clostridia and phylum Firmicutes were significantly lowered compared to healthy controls, and the ratio of Bacteroidetes to Firmicutes increased with increasing concentrations of blood glucose (37). Examples of bacteria found to be overall reduced in type 2 diabetes subjects are Roseburia intestinalis and Faecalibacterium prausnitzii, both butyrate-producing bacteria (38). Not only does the diabetic state of an individual influence the composi- tion of their gut microbiota, but potentially the diabetic state of their mother as well. The meconium obtained from infants born to mothers with type 2 diabetes were enriched with the Bacteroidetes and Parabacteriodes phyla, as compared to infants born to non-diabetic mothers (39).

It should be noted that there is also some evidence of altered gut microbiota in children suffering from type 1 diabetes compared to healthy controls. Similar to the microbiota of their type 2 diabetic counterparts, the ratio of Bacteroidetes to Firmicutes increased in type 1 patients compared to healthy controls, with a marked increase in the overall number of Bacteroidetes, and the ratio of Bacteroidetes to Firmicutes positively correlated with blood glucose concentration (40). Also, another similar pattern was observed between type 1 and 2 diabetics, both showing lowered numbers of butyrateproducing bacteria $(40,41)$. Type 1 patients were observed to have a significant increase in Veillonella and Clostridium levels, and a robust decrease in the numbers of Lactobacillus, Bifidobacterium, Blautia coccoides/Eubacterium rectale group and Prevotella (40).

Additionally, the predisposition to developing type 1 diabetes may actually be dependent on the pre-existing gut microbiota of an individual. Wen et al demonstrated that MyD88 (an adapter protein for immune-receptors that recognize microbial stimuli) knock out non-obese diabetic (NOD) mice, which can spontaneously develop type 1 diabetes, do not develop type 1 diabetes when their gut is populated with a microbiota profile matching that of the healthy human gut; however, germ free MyD88-negative NOD mice developed highly progressed type 1 diabetes (42). The resistance to type 1 diabetes found in the first group of MyD88-negative mice could be transferred to wild type NOD mice through fecal transfer, delaying and offsetting the symptoms of type 1 diabetes (43). These findings suggest that microbiota is indeed involved, and microbial dysbiosis may progress type 1 diabetes development, but that gut microbial restoration may alleviate symptoms.

Interestingly, current diabetic treatments may be inadvertently taking advantage of the gut microbiota relationship with glucose metabolism. Metformin's mode of action has long been debated, long thought to interact with either AMPK or the mitochondria to lower blood glucose levels (44). However, a report from 1984 observing the lack of therapeutic effect from intravenous metformin in comparison to oral administration, which has had surprisingly little follow up until recently, brings these primary theories into question (45). A version of metformin with higher bioavailability is less effective than 
unmodified metformin which remains in the gut for longer (46). Napolitano et al have shown that metformin modified the secretion of entero-endocrine hormones, increasing glucagon-like peptide 1 (GLP-1) expression and activation, and decreasing serum bile acid levels, specifically cholic acid and its conjugates (47), rare examples of carcinogenic endobiotics (48). Together these studies establish the correlation between diabetes and gut microbiota and their modulation to ease glucose intolerance in diabetic patients.

\section{Colorectal cancer and gut microbiota}

Colorectal cancer (CRC) is one of the most common fatal malignancies in the world (49). The involvement of gut microbiota in the development of colorectal cancer has been noted for some time $(50,51)$. Interleukin-10-deficient mice and TCR $\beta / p 53$ double knockout mice do not develop colorectal cancer under a germfree environment, providing a rationale for the association between colorectal cancer and gut microbiota (52). Chronic inflammation is known to predispose an individual to cancer, and as such, the presence of IBD increases the risk of colorectal cancer. Another such example would be colitis associated cancer (CAC). A recent study demonstrated that dysbiosis of gut micobiota plays a key role in the pathophysiology of CAC (53). Bacterial diversity is remarkably decreased in the gut microbiota of sporadic colorectal cancer and CAC mice models. When gnotobiotic mice are colonized with feces taken from sporadic colorectal cancer or CAC mice, the incidence and number of tumours are increased in both cases, compared with those colonized with feces of healthy mice. Results from a timecourse analysis of the composition of gut microbiota during development of CAC indicated that tumour-bearing mice showed enrichment in operational taxonomic units (OTUs) affiliated with members of the Bacteroides, Odoribacter, and Allobaculum genera, and decreases in OTUs affiliated with members of the Prevotellaceae and Porphyromonadaceae families (54). Furthermore, conventionalization (colonization of germfree mice with gut microbiota) with tumour-bearing mice significantly increased colon tumourigenesis compared to those colonized with feces from healthy mice (55). These findings suggest that gut microbiota plays a part in the initiation of colorectal cancer. CAC results from the complex relationship between chronic inflammation and dysbiosis of gut microbiota, which would induce irreversible changes to intestinal epithelial cells. Bacteroides fragilis toxin, produced by enterotoxigenic $B$. fragilis (ETBF), induces colorectal cancer by binding to colonic epithelial cells and stimulating cleavage of the cell adhesion molecule E-cadherin, which normally acts as a tumour suppressor protein [56]. Antibodymediated blockade of interleukin-17 (IL-17), a key cytokine for proinflammatory responses, inhibits ETBF-induced colitis and tumour formation (57). Gut microbiota of IL-10 deficient mice developing spontaneously severe colitis have decreases in bacterial diversity, and increases in the occupancy of Enterobacteriaceae (58). Interleukin-10 deficient mice, colonized with either Escherichia coli or Enterococcus faecalis, develop colon inflammation, but only the mice receiving E. coli developed colon tumours. Moreover, it was reported that colibactin, the product of polyketide synthase (PKS) in E. coli NC101, cleaved double stranded DNA in colonic epithelial cells and promoted invasive carcinoma in IL-10 deficient mice (59). Because the expression of the ETBF toxin gene and PKS gene of E. coli NC101 is higher in patients with colorectal cancer when compared to healthy adults, aberrant proliferation of these bacteria caused by dysbiosis of gut microbiota would induce disruption of epithelial barrier function, and contribute to the underlying mechanisms of CAC development.

To date, human studies examining the effects of dysbiosis with respect to $\mathrm{CRC}$ have been limited to small cohorts, with evidence of sampling heterogeneity and limited tumour phenotyping. However, still a small number of specific pathobionts have now been linked with adenomas and CRC, including Streptococcus gallolyticus [60], Enterococcus faecalis [61] and B. fragilis (57). Escherichia coli is also overpopulated on CRC mucosa; E. coli expresses genes that confer properties relevant to oncological transformation, including $\mathrm{M}$ cell translocation, angiogenesis and genotoxicity (62). Enrichment of Fusobacterium nucleatum has also been identified in adenoma versus adjacent normal tissue, and is more abundant in stools from CRC and adenoma patients than from healthy controls. Fusobacterium nucleatum's FadA, a unique adhesin, allows $E$. coli to adhere to and invade human epithelial cells, eliciting an inflammatory response (63) and stimulating cell proliferation (64). Novel mechanisms from previously un-associated bacteria are also being described to explain how bacterial proteins target proliferating stemprogenitor cells. For example, AvrA, a pathogenic product of Salmonella, has been shown to activate $\beta$-catenin signals and enhance colonic tumorigenesis (65). Taken together, it is likely that modulating the gut microbiota will become an effective tool to prevent and combat CRC. 
Table 1. Association between gut microbial dysbiosis and disease

\begin{tabular}{|c|c|}
\hline Disease & Taxonomic changes in disease state microbiota \\
\hline Obesity & $\begin{array}{l}\text { High Firmicute-Bacteroides ratio } \\
\text { Lower butyrate bacteria related to Roseburia intestinalis }\end{array}$ \\
\hline $\begin{array}{l}\text { Type } 2 \\
\text { diabetes }\end{array}$ & $\begin{array}{l}\text { Lower class Clostridia and phylum Firmicutes } \\
\text { High ratio of Bacteroides-Firmicutes; +ve correlation with } \\
\text { blood glucose concentration } \\
\text { Reduced Roseburia intestinalis and Faecalibacterium } \\
\text { prausnitzii }\end{array}$ \\
\hline $\begin{array}{l}\text { Type } 1 \\
\text { diabetes }\end{array}$ & $\begin{array}{l}\text { High ratio of Bacteroides-Firmicutes; +ve correlation wit } \\
\text { blood glucose concentration } \\
\text { Increase in Bacteroides populationz } \\
\text { Increase in Veillonella and Clostridium } \\
\text { Decrease in Lactobacillus, Bifidobacterium, Blautia } \\
\text { coccoides/Eubacterium rectale group and Prevotella }\end{array}$ \\
\hline $\begin{array}{l}\text { Colorectal } \\
\text { cancer }\end{array}$ & $\begin{array}{l}\text { Increase in Bacteroides, Odoribacter, and Allobaculum } \\
\text { genera } \\
\text { Decrease in Prevotellaceae and Porphyromonadaceae } \\
\text { families } \\
\text { Increase in Bacteroides fragilis and Bacteroides fragilis } \\
\text { toxin } \\
\text { Increase in Enterobacteriaceae } \\
\text { Increase in Streptococcus gallolyticus, Enterococcus } \\
\text { faecalis and Bacteroides fragilis } \\
\text { Colorectal cancer mucosa associated Escherichia coli } \\
\text { and Fusobacterium nucleatum }\end{array}$ \\
\hline $\begin{array}{l}\text { Irritable } \\
\text { bowel } \\
\text { syndrome }\end{array}$ & $\begin{array}{l}\text { Increased Clostridium, Dorea, and Ruminococcus, } \\
\text { Decreased Bifidobacterium, Faecalibacterium and } \\
\text { methanogens } \\
\text { Decrease in Roseburia, E. rectale, H2-consuming } \\
\text { bacteria, methanogens and reductive acetogens (C-IBS) }\end{array}$ \\
\hline $\begin{array}{l}\text { Inflammatory } \\
\text { bowel } \\
\text { disease }\end{array}$ & $\begin{array}{l}\text { Increased Actinobacteria and Proteobacteria } \\
\text { Increased Candida, Penicillium and Saccharomyces } \\
\text { Decreased Bacteroidetes and Lachnospiraceae } \\
\text { Crohn's disease specific changes } \\
\text { Increase in Ruminococcus gnavus } \\
\text { Decrease in Dialister invisus, Faecalibacterium prausnitzii } \\
\text { and Bifidobacterium adolescentis } \\
\text { Ulcerative colitis specific changes } \\
\text { Increased Escherichia sp, Helicobacter sp, Campylobacter } \\
\text { sp, and Pseudomonas aeruginosa } \\
\text { Decreased Firmicutes and Bacteroidetes } \\
\text { Decreased Clostridium coccoides, Clostridium leptum, } \\
\text { Roseburia, Ruminococcus, Enterococcus, Lactobacillis, } \\
\text { and Faecalibacterium prausnitzii }\end{array}$ \\
\hline $\begin{array}{l}\text { Clostridium } \\
\text { difficile } \\
\text { infection }\end{array}$ & Increased Clostridium difficile \\
\hline
\end{tabular}

\section{MICROBIOTA AND GUT INFLAMMATION}

\section{Inflammatory bowel syndrome}

Irritable bowel syndrome (IBS) is a non-inflammatory condition for which investigators have long been in search of plausible underlying pathogeneses, and it is inevitable that altered composition or function of the gut microbiota will be considered as a potential aetiological factor in at least a subset of patients with IBS. Compared to healthy controls, the collective gut microbiota of IBS patients is characterized by higher populations of Clostridium, Dorea, and Ruminococcus, and a decrease in Bifidobacterium, Faecalibacterium and methanogens (66). In Constipated-IBS (C-IBS), the numbers of lactate-producing and lactate-utilising bacteria, and the number of $\mathrm{H} 2$-consuming populations, methanogens and reductive acetogens, were at least 10 -fold lower compared with control subjects. Also, the number of lactate- and $\mathrm{H} 2$-utilising sulphate-reducing populations was increased 10 to 100 fold in C-IBS patients compared with healthy subjects. The butyrate-producing Roseburia, E. rectale group was lower in C-IBS patients than in controls. Constipated-IBS fecal microbiota produced more sulphides and $\mathrm{H} 2$, and less butyrate from starch fermentation, compared to healthy control fecal microbiota (67).

\section{Inflammatory bowel disease}

Inflammatory bowel disease (IBD) is a chronic disorder marked by debilitating inflammation to the gastrointestinal tract, often resulting in recurring symptoms such as severe abdominal pain, gastrointestinal bleeding, and diarrhoea (68). The term IBD is primarily used to describe two distinct conditions with similar symptoms, ulcerative colitis (UC) and Crohn's disease (CD) (69). Little is known of the aetiology of IBD, especially UC, which is marked by phases of relapse and symptom free remission (70). Ulcerative colitis inflammation usually affects the colorectum and is commonly diagnosed in young adults (71). Unlike UC, which is restricted to the colon, CD may affect any portion of the gastrointestinal tract, including the mouth and perianal area (72). Although the root cause of IBD is unclear, it is recognized that the onset of IBD is multifactorial, as immune system alteration and dybiosis of gut flora in genetically susceptible individuals, and environmental factors all play a role. A genetic component contributing to the susceptibility to developing IBD has been demonstrated through large scale genome analyses, which have revealed over 200 genetic loci in humans that are associated with IBD (73). Many of these genes are involved in the regulation of innate immune system functions, such as cytokine release, intestinal 
barrier defense and microbial recognition (74). This is supported by a study that observed the loss of immune tolerance by the mucosal immune system in IBD patients (75). Given the established role that immune dysfunction plays in the progression of IBD, primary treatment strategies for both disorders have revolved around the administration of aminosalicylates, corticosteroids, and immune-suppressants (76-78). However, the current treatment and management options available for $\mathrm{CD}$ and UC are plagued by side effects, lack of efficacy, and frequent symptom relapse (78-80).

In an attempt to avoid or minimize IBD treatment side effects, and improve overall patient quality of life, remediating dysbiosis of the gut microbiota is being considered as an alternative treatment approach. Rationale for targeting the microbiota of the gut arises from the observed higher rates of IBD in developed western countries, where microbiota influencing factors such as diet, hygiene, and environment differ. The microbiota influencing effects of environment are exemplified in a 2011 study which observed that individuals immigrating from developing countries to westernized countries in Europe experienced an increased chance of developing IBD, especially UC, compared to those immigrating to other developing countries (81). A westernized diet high in fats and refined carbohydrates is strongly associated with IBD compared to diets consisting primarily of complex carbohydrates and poly-unsaturated fats (82). Furthermore, it has been shown that a distinct enterotype of gut microbiota indicative of a western diet can occur irrespective of geographic location, suggesting that diet alone may play the primary role in determining the pre-clinical makeup of gut flora [83]. Given the effect of environment and diet on gut microbiota and IBD rates, it is conceivable that shifts in gut flora are a probable factor in the establishment of a pro-IBD state and the onset and progression of IBD. Additionally, IBD patients are more likely to have taken antibiotics in the 2-5 years preceding the development of IBD symptoms compared to healthy populations, further supporting the notion that perturbation of the gut microbiota is central to IBD development (84).

Investigation into the gut microbiota of IBD patients reveals several significant changes in bacterial populations. A study investigating the gut microbiota of CD and UC patients detected a marked increase in the number of Actinobacteria and Proteobacteria, along with a significant decrease in the number of Bacteroidetes and Lachnospiraceae for both types of IBD when compared to healthy controls (85). Also, in general, IBD patients are marked by a decrease in diversity of gut microbiota and increase in fungi such as Candida,
Penicillium and Saccharomyces (86). A study examining CD patients demonstrated that there was a significant increase in Ruminococcus gnavus and a decrease of Dialister invisus, Faecalibacterium prausnitzii and Bifidobacterium adolescentis compared to their unaffected relatives and matched healthy controls (87). In UC patients, reduced numbers of firmicutes and bacteroidetes have been observed $(88,89)$, along with reduced numbers of Clostridium coccoides, Clostridium leptum, Roseburia, Ruminococcus, Enterococcus, Lactobacillis, and Faecalibacterium prausnitzii (90). Strains positively associated with UC development include Escherichia sp, Helicobacter sp, Campylobacter sp, and Pseudomonas aeruginosa (90).

\section{Clostridium difficile infection}

Clostridium difficile infection (CDI) is a gastrointestinal disease that often develops in patients treated with microbiotadisrupting antibiotic or immunosuppressant medications who come in contact with $C$. difficile spores, and is the most common cause of hospital acquired diarrhoea (91). Compared with those from control subjects and patients with an initial episode, the fecal communities in patients with recurrent Clostridium difficile associated diarrhoea were highly variable in bacterial composition and were characterized by markedly decreased diversity (92). Preservation and restoration of the microbial diversity could represent novel strategies for prevention and treatment of recurrent CDI. Fecal microbial transplantation administered to CDI patients, sourced from healthy individuals, is an effective way of treating. Apart from this, probiotics have also emerged as another promising treatment for CDI that works by restoring gut microbiota to a healthy state.

\section{GUT MICROBIAL REMEDIATION}

\section{Prebiotics}

The notion of prebiotics was put forth by Marcel Roberfroid in 1995, and defined as "non-digestible food ingredients that benefit the host by selectively stimulating the growth or activity of one or a limited number of bacteria in the colon" (93). Prebiotics include, but are not limited to, dietary carbohydrates such as resistant starches, non-starch polysaccharides, and oligosaccharides; these agents act as substrates for the growth of bacteria in the large intestine, having avoided digestion by host enzymes (94). Studies concerning prebiotics have not been as extensive as research concerning probiotics or FMT, however, the studies that do exist point to prebiotics as being effective to some extent in remediating gut dysbiosis (95). It is possible that prebiotics may be useful as an adjunct 
in the administration of probiotics, acting to initiate and support probiotic growth.

\section{Probiotics}

Probiotics are "live microorganisms which provide a health benefit on the host when administered in adequate amounts", as defined by the Food and Agriculture Organization of the United Nations and the WHO (96). Conditions improved by administration of probiotics range from liver injury (97), to several neurological disorders (98). Examples of highly studied and prescribed probiotics are Lactobacillus and Bifidobacterium (99). Lactobacillus gasseri BNR17 inhibits overall weight gain and fat storage in Sprague-Dawley rats fed high-sucrose diets, and induces a reduction of glucose levels and improves diabetic symptoms in type 2 diabetes mice $(100,101)$. Metabolic changes following treatment with L. gasseri are thought to occur through stimulated expression of glucose transporter 4 (GLUT4) and fatty oxidation-related genes (ACO, CPT1, PPAR $\alpha, \operatorname{PPAR} \delta$ ), down-regulation of fatty acid synthesis-related genes (SREBP-1c and ACC), and the lowering of leptin and insulin serum levels (102). Besides the role of Lactobacillus in alleviating the diseases primarily discussed in this review, certain Lactobacillus strains have been demonstrated to ameliorate neurological conditions (103). In particular, L. rhammosus and L. casei Shirota were individually shown to alleviate anxiety and depression-like behaviour in both mice and humans respectively $(104,105$, also see 105a). Additionally, L. reuteri was shown capable of modulating the enteric nervous system, although with no clear mode of action (106).

Numerous other strains are being investigated and show promise, such as Akkermansia muciniphilia, a mucindegrading bacterium which has been shown to be reduced in individuals suffering from IBD (107) and obesity (108). Administration of antibiotics causes major collateral damage to the healthy commensal bacteria of an individual, with a resulting decrease in the diversity and species richness of the gut microbiota (109). Probiotics are being looked to as a potential agent in the alleviation of post-antibiotic disturbance to the gut microbiota. A recent large scale clinical trial involving children up to the age of 18 years evaluated the potential of several probiotics as a treatment method to alleviate antibiotic-associated diarrhea (AAD). Among the several probiotics tested, Lactobacillus rhamnosus and Saccharomyces boulardii were found to be significantly efficacious and safe in alleviating AAD when administered between dosages of 5-40 billion colony forming units/day (110). Several probiotics are being studied as potential microbiome stabilizers in human and have been proven to be effective. The list of probiotics and their gut microbial modulatory effect in patients is noted in Table 2.

Table 2. Probiotics and their efficiency in restoring gut microbiota

\begin{tabular}{|c|c|c|c|c|}
\hline Probiotics & $\begin{array}{l}\text { Pre-existing } \\
\text { disrupting factor }\end{array}$ & $\begin{array}{l}\text { Claims stated } \\
\text { in the paper }\end{array}$ & Evidence based claim & References \\
\hline Escherichia coli Nissle & Liver cirrhosis & Restores & $\begin{array}{l}\text { More Bifidobacteria and } \\
\text { Lactobacillus }\end{array}$ & $(111)$ \\
\hline Saccharomyces boulardii lyo & Active diarrhoea & Improves & More 'habitual microbiota' & $(112)$ \\
\hline $\begin{array}{l}\text { Lactobacillus plantarum 8PA3 } \\
+ \text { Bifidobacterium bifidum }\end{array}$ & Colon cancer & Restores & $\begin{array}{l}\text { More E. coli and } \\
\text { enterococci }\end{array}$ & (113) \\
\hline $\begin{array}{l}\text { L. brevis CD2+Lactobacillus salivaris FV2+L. plantarum FV9 L. } \\
\text { paracasei Lpc37+L. acidophilus } 74-2+\text { Bifido animalis DGCC420 }\end{array}$ & IBS & Restores & $\begin{array}{l}\text { More clostridia } \\
\text { and Ruminococcus }\end{array}$ & $(114,115)$ \\
\hline $\begin{array}{l}\text { L. rhamnosus GG+L. rhamnosus } \\
\text { Lc705+Propionibacterium freudenreichii shermanii JS+B. } \\
\text { breve Bb99 }\end{array}$ & IBS & Restores & More clostridia & $(116-118)$ \\
\hline $\begin{array}{l}\text { L. acidophilus } 4356+\text { L. plantarum } \\
\text { 14917+L. rhamnosus } 7469\end{array}$ & Liver disease & Improves & $\begin{array}{l}\text { Less firmicutes, } \\
\text { more bacteriodetes }\end{array}$ & $(118)$ \\
\hline $\begin{array}{l}\text { L. acidophilus+L. paracasei } \\
+ \text { Lactobacillus delbrueckii spp } \\
\text { Bulgaricus+L. plantarum+B. } \\
\text { longum+B. infantis+B. breve }\end{array}$ & Pouchitis & Altered & More anaerobes & (119) \\
\hline $\begin{array}{l}\text { L. acidophilus+L. paracasei } \\
+ \text { Lactobacillus delbrueckii spp } \\
\text { Bulgaricus+L. plantarum+B. } \\
\text { longum+B. infantis }+B \text {. breve }\end{array}$ & IBS & Altered & Less bacteroides & $(120)$ \\
\hline
\end{tabular}




\section{Fecal microbial transplantation}

Fecal microbial (microbiota) transplantation (FMT) is the process of transferring the gut microbiota from a healthy donor to the gut of a patient suffering from dysbiosis of the gut flora, usually through liquefied fecal enema. The aim of FMT is to establish and maintain a microbiota profile matching the healthy donor within the patient, alleviating symptoms originating from microbial dysbiosis. Fecal microbial transplantation can be traced as far back as to its use in $4^{\text {th }}$ century China (121). The first modern employment of fecal transplantation was conducted in 1958 as a treatment method for pseudomembranous enterocolitis (122). Donor FMT bacteria have been shown to persist and replace or coexist with recipient populations for at least 3 months (123). Currently, FMT is being considered for medical applications including the treatment of obesity, diabetes, IBD and CDI. A small number of FMT trials have been conducted in rats to alleviate obesity and insulin resistance with some success $(30,124)$. To our knowledge there exists only one report of human FMT use to alleviate metabolic disorders. A study of FMT from lean healthy donors to patients recently diagnosed with type 2 diabetes resulted in heightened insulin sensitivity, however, non-significant weight loss was recorded after 6 weeks (125).

In the last decade, FMT therapy has shown the greatest success in the treatment of CDI at a clinical level. Clostridium difficile infections may reoccur due to instability of the gut microbiota, as often seen in immune-compromised patients following organ transplant or HIV infection (126). Fecal transplants are emerging as a safe and effective treatment method to prevent CDI recurrence, having shown success at a clinical level. A small cohort study found that $85.7 \%$ of patients receiving FMT did not have CDI recurrence following CDI brought on by immunosuppression during hematopoietic stem cell transplants (127). A large scale study observing FMT administered to a mixed group of immune-compromised patients (HIV/AIDS, organ transplant, cancer, immune-suppression for IBD) found similar results, with an overall cure rate of $89 \%$ for CDI recurrence following FMT (128). 16S rRNA gene sequencing of patient feces post FMT treatment has revealed that patient microbiota profile does indeed shift to match the donor FMT bacterial composition, which alleviates the improper metabolism of primary bile salts thought to be responsible for CDI symptoms (129). A myriad of similar studies have demonstrated the effectiveness of FMT for treating CDI, making FMT a promising treatment for widespread clinical use in the future and opening the door to other possible medical applications for FMT (128, 130-134).

The high efficacy and reproducibility of CDI abrogation through FMT treatment has sparked excitement in potentially transferring over this success to the treatment of IBD, with FMT as an alternative to drug regimens which are plagued by heavy side effects. However, to date, data concerning FMT treatment and IBD still remains limited compared to its application for CDI (90). Of the recent studies that have evaluated FMT in IBD patients at a clinical level, the results look promising, however, remission rates do not match the success of treating CDI through FMT therapy (135). A meta-analysis of IBD treatment over 2 decades indicates that CD has to date responded better from FMT, with an remission rate of $61 \%$, whereas UC remission rates have been estimated to average $22 \%$ (136). However, another meta-analysis has reported remission rates upward of $63 \%$ for IBD patients in general, in which $76 \%$ of those patients ceased taking medication for their disorder (137). Furthermore, a case study evaluating the efficacy of FMT to treat a CD patient non-responsive to immune-suppressants found that after treatment the patient underwent and maintained dramatic remission of disease symptoms (138). This finding is significant as FMT may also prove to serve as a method of treatment for patients nonresponding to conventional treatment (Fig. 1).

Despite encouraging initial clinical outcomes, there still exist some obstacles to FMT treatment and the development of administrative techniques. Currently, FMT is usually administered through a nasogastric or nasojejunal tube and to a lesser extent, through enema or colonoscopy (139). A small cohort study observed that IBD patient's expressed displeasure concerning discomfort during colonoscopy, and thus refused repeated treatment over short periods of time (84). However, it should be noted that the same study concluded that IBD patient's generally had a positive attitude towards FMT, as they viewed it as a "natural" alternative medicine. Improvement in treatment delivery could potentially occur in some cases through the use of percutaneous endoscopy cecostomy (PEC), a semi-permanent abdominal port that connects a tube to the intestinal lumen. A recent case study followed a 24 year old male UC patient with recurrent steroiddependent UC that underwent FMT via PEC once per day for a month, and observed a subsequent 12 month drug-free remission (140). Eventually, the development of an effective colorless, odourless, oral FMT pill would be ideal as it could potentially provide a standardized and non-invasive treatment method. 


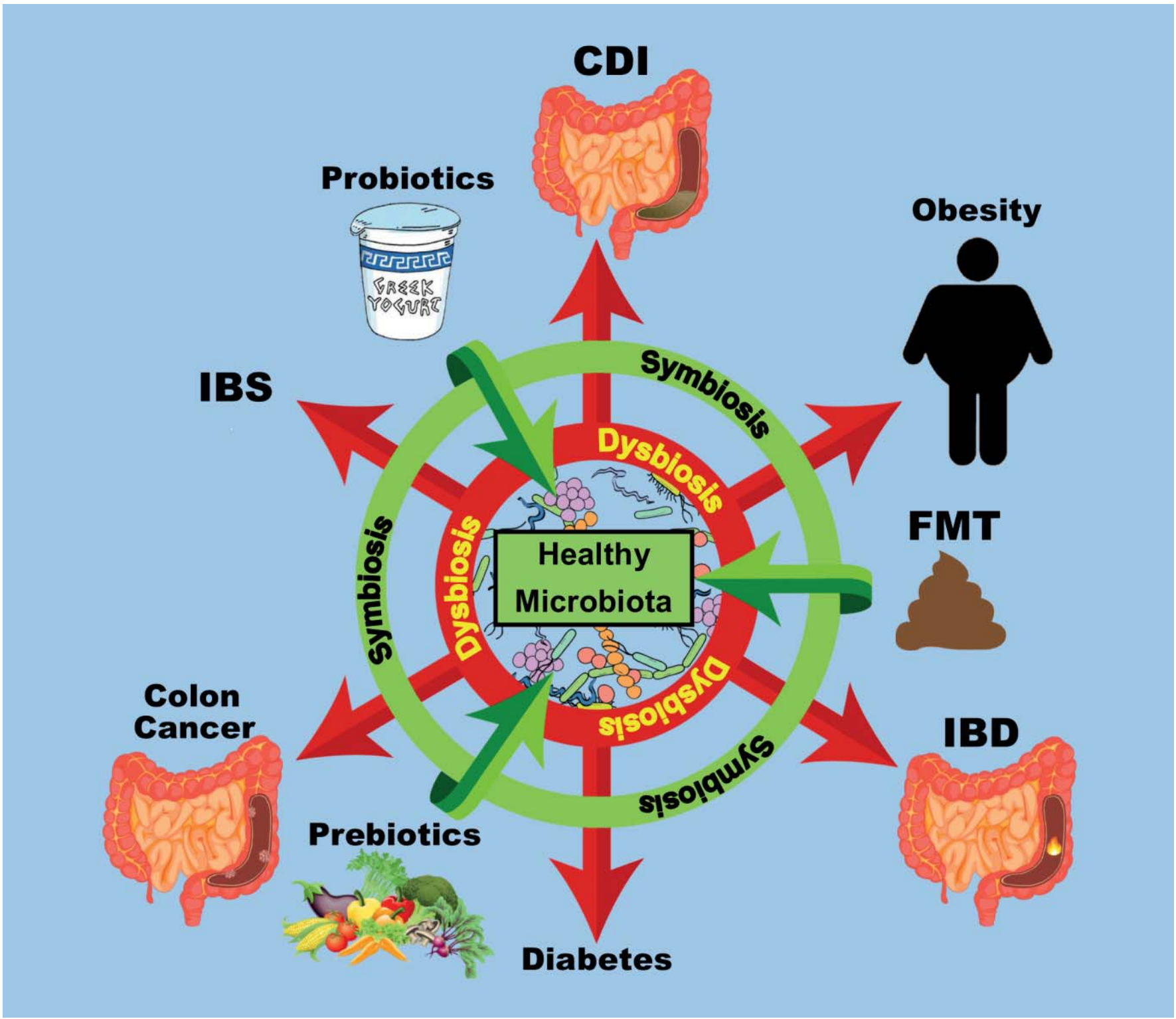

Figure 1. Change in healthy microbial composition leads to dysbiosis (red arrows) and is associated with obesity, diabetes, colorectal cancer, irritable bowel syndrome (IBS), inflammatory bowel disease (IBD) and Clostridium difficile infections (CDI). Prebiotics, probiotics and fecal microbial transplantation (FMT) remediate microbial symbiosis (green arrows) and return the microbial composition to a healthy state.

\section{CONCLUSION}

Health is a multifactorial concept, and the microbiome is emerging as a novel reservoir of information that is helpful in defining the parameters of both good health and illness. Interest in the human microbiome has increased considerably after completion of the human microbiome project in 2012. Scientists and clinicians have realized that the commensal microorganisms that comprise the human gut microbiota are not simply passengers in the host, but actually drive metabolic, immunological and some neurological functions in the host as well, such as behaviour. Dysbiosis of microbiota is associated with obesity, diabetes, CRC, IBS, IBD and CDI. Although not covered in detail, dysbiosis negatively affects several organs, such as observed in nervous system disorders (multiple sclerosis and Parkinson's disease), cardiometabolic diseases (141), and in gout and related diseases associated 
with fungal dysbiosis $(142,143)$, underscoring the belief that the microbiota should be considered as a vital endocrine organ. Prebiotics, probiotics and FMT are capable of remediating and returning the gut microbiota to a healthy state, for which they have the potential to be used as a cure for these diseases (Fig. 1). We have highlighted some key disease areas in which the microbiota and its microbiome are thought to have not just an association, but also participate in tight crosstalk to modulate key physiological processes in the host. By better understanding the mechanisms and contributions that microbiota make to these diseases, we hope to not only to elucidate the molecular meaning of health, but to also aid in the development of novel therapeutics and strategies to modulate the microbiota to treat or prevent disease. In some instances it may be possible to track changes in the microbiome to detect gut-related diseases. In the future, information regarding gut microbial composition can be used efficiently to stratify patients in order to accurately assign personalised treatments. Evidence also points to the gut microbiota being an environmental factor in drug metabolism, for example, lack of therapeutic effect from intravenous metformin in comparison to oral administration, and inactivation of the cardiac drug digoxin by Eggerthella lenta in the gut. Thus, a future vision of personalised healthcare must consider the microbiome and host genome together. The sound of microbiome in human health and disease (also see 144) is increasingly emerging indeed.

Conflicts of interest statement: The authors declare that the research was conducted in the absence of any commercial or financial relationships that could be construed as a potential conflict of interest.

\section{REFERENCES}

1. Official records of the World Health Organization. 1975; United Nations, WHO, Interim Commission.

2. Bernad AD, Dalz Z, Wieckowska B, Maksymiuk T. Perception of health by healthy and ill persons. The New Challenges 2012; p. 127.

3. Dixon JB. The effect of obesity on health outcomes. Mol Cell Endocrinol 2010; 316: 104-108.

4. Powell AD, Kahn AS, Racial differences in women's desires to be thin. Int J Eating Disord 1995; 17: 191-195.

5. Fitzgibbon, M.L., L.R. Blackman, M.E. Avellone. The relationship between body image discrepancy and body mass index across ethnic groups. Obesity Res 2000; 8: $582-589$
6. Backhed F, R.E. Ley, J.L. Sonnenburg, D.A. Peterson, J.I. Gordon, Host-bacterial mutualism in the human intestine. Science 2005; 307: 1915-1920. DOI: 10.1126/ science. 1104816

7. Qin J, Li R, JRaes J, Arumugam M, Burgdorf KS, Manichanh $\mathrm{C}$, et al. A human gut microbial gene catalogue established by metagenomic sequencing. Nature 2010; 464: 59-65. DOI: 10.1038/nature08821

8. Yatsunenko T, F.E. Rey, M.J. Manary, I. Trehan, M.G. Dominguez-Bello, M. Contreras, et al. Human gut microbiome viewed across age and geography. Nature 2012; 486: 222-227. DOI: 10.1038/nature11053

9. Koenig JE, A. Spor, N. Scalfone, A.D. Fricker, J. Stombaugh, R. Knight, et al., Succession of microbial consortia in the developing infant gut microbiome. Proc Natl Acad Sci USA 2011; 108 (Suppl 1): 4578-4585. DOI: $10.1073 /$ pnas. 1000081107

10. Reyes A, M. Haynes, N. Hanson, F.E. Angly, A.C. Heath, F. Rohwer, et al., Viruses in the faecal microbiota of monozygotic twins and their mothers. Nature 2010; 466: 334-338. DOI: 10.1038/nature09199

11. Lozupone CA, J.I. Stombaugh, J.I. Gordon, J.K. Jansson, R. Knight.Diversity, stability and resilience of the human gut microbiota. Nature 2012; 489: 220-230. DOI: 10.1038/nature 11550

12. Hallen-Adams HE, Suhr MJ. Fungi in the healthy human gastrointestinal tract. Virulence 2016; DOI: 10.1080/21505594.2016.1247140

13. Arumugam M, J. Raes, E. Pelletier, D. Le Paslier, T. Yamada, D.R. Mende, et al. Enterotypes of the human gut microbiome. Nature 2011; 473: 174-180

14. Eckburg PB, E.M. Bik, C.N. Bernstein, E. Purdom, L. Dethlefsen, M. Sargent, et al. Diversity of the human intestinal microbial flora. Science 2005; 308: 1635-1638. DOI: $10.1126 /$ science. 1110591

15. Le Chatelier E, T. Nielsen, J. Qin, E. Prifti, F. Hildebrand, G. Falony, et al., Richness of human gut microbiome correlates with metabolic markers. Nature 2013. 500: 541-546. 10.1038/nature12506

16. Cotillard A, S.P. Kennedy, L.C. Kong, E. Prifti, N. Pons, E. Le Chatelier, et al. Dietary intervention impact on gut microbial gene richness. Nature 2013; 500: 585-588. DOI: $10.1038 /$ nature 12480

17. Turnbaugh PJ, M. Hamady, T. Yatsunenko, B.L. Cantarel, A. Duncan, R.E. Ley, et al. A core gut microbiome in obese and lean twins. Nature 2009. 457: 480-484. 10.1038 /nature 07540 
18. Belzer C, de Vos WM. Microbes inside - from diversity to function: the case of Akkermansia. ISME J 2012; 6: 1449-1458. DOI: 10.1038/ismej.2012.6

19. Coyte KZ, J. Schluter, K.R. Foster, The ecology of the microbiome: Networks, competition, and stability. Science 2015; 350: 663-666. DOI: 10.1126/science.aad2602

20. Cantarel BL, E. Waubant, C. Chehoud, J. Kuczynski, T.Z. DeSantis, J. Warrington, et al. Gut microbiota in multiple sclerosis: possible influence of immunomodulators. J Invest Med 2016; 63: 729-734. DOI: 10.1097/ JIM.0000000000000192

21. Sampson TR, J.W. Debelius, T. Thron, S. Janssen, G.G. Shastri, Z.E. Ilhan, et al. Gut Microbiota regulate motor deficits and neuroinflammation in a model of Parkinson's disease. Cell 2016; 167: 1469-1480. DOI: 10.1016/j. cell.2016.11.018

22. WHO. Global Status Report on Noncommunicable Diseases 2016 (cited; Available from: http:/www.who.int/ mediacentre/factsheets/fs311/en/)

23. Ng M, Fleming T, M. Robinson, B. Thomson, N. Graetz, et al. Global, regional and national prevalence of overweight and obesity in children and adults 19802013: A systematic analysis for the Global Burden of Disease Study 2013. Lancet 2014; 384: 766-781. DOI: 10.1016/S0140-6736(14)60460-8

24. Naukkarinen J, A. Rissanen, J. Kaprio, K.H. Pietilainen, Causes and consequences of obesity: the contribution of recent twin studies. Int J Obes (Lond) 2012; 36: 10171024. DOI: 10.1038/ijo.2011.192

25. Popkin BM, Adair LS, Ng SW. Global nutrition transition and the pandemic of obesity in developing countries. Nutr Rev 2012. 70: 3-21. DOI: 10.1111/j.17534887.2011.00456.x

26. Luke A, R.S. Cooper, T.E. Prewitt, A.A. Adeyemo, T.E. Forrester, Nutritional consequences of the African diaspora. Annu Rev Nutr 2001; 21: 47-71. DOI: 10.1146/ annurev.nutr.21.1.47

27. Ley RE, P.J. Turnbaugh, S. Klein, J.I. Gordon. Microbial ecology: human gut microbes associated with obesity. Nature 2006. 444: 1022-1023 1DOI: 0.1038/4441022a

28. Turnbaugh PJ, R.E. Ley, M.A. Mahowald, V. Magrini, E.R. Mardis, J.I. Gordon. An obesity-associated gut microbiome with increased capacity for energy harvest. $\mathrm{Na}$ ture 2006; 444: 1027-1031. DOI: 10.1038/nature05414

29. Backhed F, H. Ding, T. Wang, L.V. Hooper, G.Y. Koh, A. Nagy, et al. The gut microbiota as an environmental factor that regulates fat storage. Proc Natl Acad
Sci USA. 2004; 101: 15718-15723. DOI: 10.1073/ pnas.0407076101

30. Ridaura VK, J.J. Faith, F.E. Rey, J. Cheng, A.E. Duncan, A.L. Kau, et al. Gut microbiota from twins discordant for obesity modulate metabolism in mice. Science 2013; 341: 1241214. DOI: 10.1126/science. 1241214

31. Suzuki TA, Worobey M. Geographical variation of human gut microbial composition. Biol Lett 2014; 10: 20131037. DOI: 10.1098/rsbl.2013.1037

32. Backhed F, J.K. Manchester, C.F. Semenkovich, J.I. Gordon. Mechanisms underlying the resistance to diet-induced obesity in germ-free mice. Proc Natl Acad Sci USA 2007; 104: 979-984. DOI: 10.1073/pnas.0605374104

33. Le Chatelier E, T. Nielsen, J. Qin, E. Prifti, F. Hildebrand, G. Falony, et al. Richness of human gut microbiome correlates with metabolic markers. Nature 2013; 500: 541-546

34. Cotillard AL, S.P. Kennedy, L.C. Kong, E. Prifti, N. Pons, E. Le Chatelier, et al. Dietary intervention impact on gut microbial gene richness. Nature 2013. 500: 585-588.

35. Vrieze A, E. Van Nood, F. Holleman, J. Salojarvi, R.S. Kootte, J.F.W.M. Bartelsman, et al. Transfer of intestinal microbiota from lean donors increases insulin sensitivity in individuals with metabolic syndrome. Gastroenterology 2012; 143: 913-916.

36. Zhang X, Shen D, Fang Z, Jie Z, Qiu X, Zhang C, et al. Human gut microbiota changes reveal the progression of glucose intolerance. PLoS One 2013; 8: e71108. DOI: 10.1371/journal.pone.0071108

37. Larsen N, F.K. Vogensen, F.W. van den Berg, D.S. Nielsen, A.S. Andreasen, B.K. Pedersen, et al. Gut microbiota in human adults with type 2 diabetes differs from non-diabetic adults. PLoS One 2010; 5: e9085. DOI: 10.1371/journal.pone.0009085

38. Tilg H, Moschen AR. Microbiota and diabetes: an evolving relationship. Gut 2014; 63: 1513-1521. DOI: 10.1136/gutjnl-2014-306928

39. Hu J, Y. Nomura, A. Bashir, H. Fernandez-Hernandez, S. Itzkowitz, Z. Pei, et al. Diversified microbiota of meconium is affected by maternal diabetes status. PLoS One 2013; 8: e78257. DOI: 10.1371/journal. pone. 0078257

40. Murri M, I. Leiva, J.M. Gomez-Zumaquero, F.J. Tinahones, F. Cardona, F. Soriguer, et al. Gut microbiota in children with type 1 diabetes differs from that in healthy children: a case-control study. BMC Medicine 2013; 11: 46-46. DOI: 10.1186/1741-7015-11-46 
41. de Goffau MC, S. Fuentes, B. van den Bogert, H. Honkanen, W.M. de Vos, G.W. Welling, et al. Aberrant gut microbiota composition at the onset of type 1 diabetes in young children. Diabetologia 2014. 57: 1569-77 10.1007/s00125-014-3274-0

42. Wen L, R.E. Ley, P.Y. Volchkov, P.B. Stranges, L. Avanesyan, A.C. Stonebraker, et al. Innate immunity and intestinal microbiota in the development of type 1 diabetes. Nature 2008. 455: 1109-1113. DOI: 10.1038/ nature 07336

43. Peng J, S. Narasimhan, J.R. Marchesi, A. Benson, F.S. Wong, L. Wen. Long term effect of gut microbiota transfer on diabetes development. J Autoimmun 2014. 53: 85-94. DOI: 10.1016/j.jaut.2014.03.005

44. Pernicova I, Korbonits M. Metformin - mode of action and clinical implications for diabetes and cancer. Nat Rev Endocrinol 2014. 10: 143-56. DOI: 10.1038/ nrendo.2013.256

45. Bonora E, M. Cigolini, O. Bosello, C. Zancanaro, L. Capretti, I. Zavaroni, et al. Lack of effect of intravenous metformin on plasma concentrations of glucose, insulin, C-peptide, glucagon and growth hormone in non-diabetic subjects. Curr Med Res Opin 1984. 9: 47-51. DOI: 10.1185/03007998409109558

46. Buse JB, R.A. DeFronzo, J. Rosenstock, T. Kim, C. Burns, S. Skare, et al. The primary glucose-lowering effect of metformin resides in the gut, not the circulation: Results from Short-term Pharmacokinetic and 12-Week Dose-Ranging Studies. Diab Care 2016; 39: 198-205. DOI: $10.2337 / \mathrm{dc} 15-0488$

47. Napolitano A, S. Miller, A.W. Nicholls, D. Baker, S. Van Horn, E. Thomas, et al. Novel gut-based pharmacology of metformin in patients with type 2 diabetes mellitus. PLoS One 2014; 9: e100778. DOI: 10.1371/journal. pone.0100778:

48. Ajouz, H., D. Mukherji, A. Shamseddine. Secondary bile acids: an underrecognized cause of colon cancer. World J Surg Oncol 2014. 12: 164-164. DOI: 10.1186/14777819-12-164

49. Jemal, A., R. Siegel, E. Ward, Y. Hao, J. Xu, T. Murray, et al. Cancer statistics, 2008. Cancer J Clinicians 2008; 58: 71-96.

50. Rubirola AB. Intestinal microbiota in the adenoma progression to colorectal cancer: a cross-sectional study. 2014; DOI: http://hdl.handle.net/10256/10416

51. Gagniare J, J. Raisch, J. Veziant, N. Barnich, R. Bonnet, E. Buc, et al. Gut microbiota imbalance and colorectal cancer. World J Gastroenterol 2016; 22: 501-518. DOI: 10.3748/wjg.v22.i2.501

52. Kado S, K. Uchida, H. Funabashi, S. Iwata, Y. Nagata, M. Ando, et al. Intestinal microflora are necessary for development of spontaneous adenocarcinoma of the large intestine in T-cell receptor chain and p53 doubleknockout mice. Cancer Res 2001; 61: 2395-2398.

53. Zhu Y, Luo TM, Jobin C, Young HA. Gut microbiota and probiotics in colon tumorigenesis. Cancer Lett 2011; 309:119-127. DOI: 10.1016/j.canlet.2011.06.004

54. Saleh M, Trinchieri G. Innate immune mechanisms of colitis and colitis-associated colorectal cancer. Nat Rev Immunol 2011; 11: 9-20. DOI: 10.1038/nri2891

55. Zackular JP, N.T. Baxter, K.D. Iverson, W.D. Sadler, J.F. Petrosino, G.Y. Chen, et al. The gut microbiome modulates colon tumorigenesis. MBio 2013; 4:e069213. DOI: $10.1128 / \mathrm{mBio} .00692-13$

56. Rhee K-J, S. Wu, X. Wu, D.L. Huso, B. Karim, A.A. Franco, et al. Induction of persistent colitis by a human commensal, enterotoxigenic Bacteroides fragilis, in wildtype C57BL/6 mice. Infect Immun 2009; 77: 1708-1718.

57. Wu S, K.-J. Rhee, E. Albesiano, S. Rabizadeh, X. Wu, H.-R. Yen, et al. A human colonic commensal promotes colon tumorigenesis via activation of T helper type $17 \mathrm{~T}$ cell responses. Nat Med 2009; 15: 1016-1022

58. Arthur JC, E. Perez-Chanona, M. Mahlbauer, S. Tomkovich, J.M. Uronis, T.-J. Fan, et al. Intestinal inflammation targets cancer-inducing activity of the microbiota. Science 2012. 338: 120-123.

59. Arthur JC, R.Z. Gharaibeh, M. Mahlbauer, E. PerezChanona, J.M. Uronis, J. McCafferty, et al. Microbial genomic analysis reveals the essential role of inflammation in bacteria-induced colorectal cancer. Nat Commun 2014; 5: 4724. DOI: 10.1038/ncomms5724

60. Boleij, A. and H. Tjalsma, The itinerary of Streptococcus gallolyticus infection in patients with colonic malignant disease. Lancet Infect Dis 2013; 13: 719-724.

61. Wang X, Yang Y, Huycke MM. Commensal bacteria drive endogenous transformation and tumour stem cell marker expression through a bystander effect. Gut 2015; 64: 459-468.

62. Prorok-Hamon M, M.K. Friswell, A. Alswied, C.L. Roberts, F. Song, P.K. Flanagan, et al. Colonic mucosaassociated diffusely adherent afaC + Escherichia coli expressing lpfA and pks are increased in inflammatory bowel disease and colon cancer. Gut 2014; 63: 761-770. DOI: 10.1136/gutjnl-2013-304739 
63. Han YW, W. Shi, G.T.J. Huang, S.K. Haake, N.-H. Park, H. Kuramitsu, et al., Interactions between periodontal bacteria and human oral epithelial cells: Fusobacterium nucleatum adheres to and invades epithelial cells. Infect Immun 2000. 68: 3140-3146.

64. Rubinstein MR, X. Wang, W. Liu, Y. Hao, G. Cai, Y.W. Han, Fusobacterium nucleatum promotes colorectal carcinogenesis by modulating E-cadherin/ $/ \hat{\mathrm{I}}^{2}$-catenin signaling via its FadA adhesin. Cell Host Microbe 2013; 14: 195-206.

65. Lu R, Wu S, Zhang YG, Xia Y, Liu X, Zheng Y, et al. Enteric bacterial protein AvrA promotes colonic tumorigenesis and activates colonic beta-catenin signaling pathway. Oncogenesis 2014. 3: e105.

66. Rajilic-Stojanovic, M., E. Biagi, H.G. Heilig, K. Kajander, R.A. Kekkonen, S. Tims, et al. Global and deep molecular analysis of microbiota signatures in fecal samples from patients with irritable bowel syndrome. Gastroenterology 2011. 141: 1792-1801. DOI: 10.1053/j. gastro.2011.07.043

67. Chassard C, M. Dapoigny, K.P. Scott, L. Crouzet, C. Del'Homme, P. Marquet, et al. Functional dysbiosis within the gut microbiota of patients with constipated irritable bowel syndrome. Aliment Pharmacol Ther 2012; 35: 828-838.

68. Shih DQ, S.R. Targan, D. McGovern. Recent advances in IBD pathogenesis: genetics and immunobiology. Curr Gastroenterol Rep 2008. 10: 568-575.

69. Lopez J, Grinspan A. Fecal microbiota transplantation for inflammatory bowel disease. Gastroenterol Hepatol (NY) 2016; 12: 374-379.

70. Tinsley A, S. Naymagon, B. Mathers, M. Kingsley, B.E. Sands, T.A. Ullman, Early readmission in patients hospitalized for ulcerative colitis: incidence and risk factors. Scand J Gastroenterol 2015; 50: 1103-1109. DOI: 10.3109/00365521.2015.1020862

71. Kane SV, Systematic review: adherence issues in the treatment of ulcerative colitis. Aliment Pharmacol Ther 2006; 23: 577-585. DOI: 10.1111/j.13652036.2006.02809.x

72. Tana C, Y. Umesaki, A. Imaoka, T. Handa, M. Kanazawa, S. Fukudo. Altered profiles of intestinal microbiota and organic acids may be the origin of symptoms in irritable bowel syndrome. Neurogastroenterol Motil 2010; 22: 512-519. DOI: 10.1111/j.1365-2982.2009.01427.x

73. Loddo I, Romano C. Inflammatory bowel disease: Genet- ics, epigenetics, and pathogenesis. Front Immunol 2015; 6: 551. DOI: 10.3389/fimmu.2015.00551:

74. Cho JH, Brant SR. Recent insights into the genetics of inflammatory bowel disease. Gastroenterology 2011; 140: 1704-1712 DOI: 10.1053/j.gastro.2011.02.046

75. Sartor RB. Genetics and environmental interactions shape the intestinal microbiome to promote inflammatory bowel disease versus mucosal homeostasis. Gastroenterology 2010; 139: 1816-1819. DOI: 10.1053/j. gastro.2010.10.036

76. Talley, N.J., M.T. Abreu, J.P. Achkar, C.N. Bernstein, M.C. Dubinsky, S.B. Hanauer, et al. An evidence-based systematic review on medical therapies for inflammatory bowel disease. Am J Gastroenterol 2011; 106 (Suppl 1): S2-25. DOI: 10.1038/ajg.2011.58

77. Mazal J. Crohn disease: pathophysiology, diagnosis, and treatment. Radiol Technol 2014; 85: 297-316.

78. Garud S, Peppercorn MA. Ulcerative colitis: Current treatment strategies and future prospects. Ther Adv Gastroenterol 2009; 2: 99-108. DOI: 10.1177/1756283X09102329

79. Lichtenstein GR, S.B. Hanauer, W.J. Sandborn. Management of Crohn's disease in adults. Am J Gastroenterol 2009; 104: 465-483. DOI: 10.1038/ajg.2008.168

80. Kornbluth A, Sachar DB. Ulcerative colitis practice guidelines in adults: American College of Gastroenterology, Practice Parameters Committee. Am J Gastroenterol 2010. 105: 501-523. DOI: 10.1038/ajg.2009.727

81. Barreiro-de Acosta M, A. Alvarez Castro, R. Souto, M. Iglesias, A. Lorenzo, J.E. Dominguez-Munoz. Emigration to western industrialized countries: A risk factor for developing inflammatory bowel disease. J Crohns Colitis 2011; 5: 566-569. DOI: 10.1016/j.crohns.2011.05.009

82. Legaki E, Gazouli M. Influence of environmental factors in the development of inflammatory bowel diseases. World J Gastrointest Pharmacol Ther 2016; 7: 112-125. DOI: 10.4292/wjgpt.v7.i1.112

83. Siddharth J, N. Holway, S.J. Parkinson, A Western diet ecological module identified from the 'humanized' mouse microbiota predicts diet in adults and formula feeding in children. PLoS One 2013. 8: e83689. DOI: 10.1371/journal.pone.0083689

84. Wei Y, W. Zhu, J. Gong, D. Guo, L. Gu, N. Li, et al. Fecal microbiota transplantation Improves the quality of life in patients with inflammatory bowel disease. Gastroenterol Res Pract 2015; 2015: 517597. DOI: 10.1155/2015/517597 
85. Frank DN, A.L. St Amand, R.A. Feldman, E.C. Boedeker, N. Harpaz, N.R. Pace, Molecular-phylogenetic characterization of microbial community imbalances in human inflammatory bowel diseases. Proc Natl Acad Sci USA 2007. 104: 13780-13785 DOI: 10.1073/ pnas.0706625104

86. Sokol H, B. Pigneur, L. Watterlot, O. Lakhdari, L.G. Bermudez-Humaran, J.J. Gratadoux, et al. Faecalibacterium prausnitzii is an anti-inflammatory commensal bacterium identified by gut microbiota analysis of Crohn disease patients. Proc Natl Acad Sci USA 2008; 105: 16731-16736. DOI: 10.1073/pnas.0804812105

87. Joossens M, G. Huys, M. Cnockaert, V. De Preter, K. Verbeke, P. Rutgeerts, et al. Dysbiosis of the faecal microbiota in patients with Crohn's disease and their unaffected relatives. Gut 2011; 60: 631-637. DOI: 10.1136/ gut.2010.223263

88. Rajilic-Stojanovic M, F. Shanahan, F. Guarner, W.M. de Vos. Phylogenetic analysis of dysbiosis in ulcerative colitis during remission. Inflamm Bowel Dis 2013; 19: 481-488 DOI: 10.1097/MIB.0b013e31827fec6d

89. Kostic AD, Xavier RJ, Gevers D. The microbiome in inflammatory bowel disease: current status and the future ahead. Gastroenterology 2014; 146: 1489-1499. DOI: 10.1053/j.gastro.2014.02.009

90. Scaldaferri F, S. Pecere, V. Petito, D. Zambrano, L. Fiore, L.R. Lopetuso, et al. Efficacy and mechanisms of action of fecal microbiota transplantation in ulcerative colitis: Pitfalls and promises from a First Meta-Analysis. Transplant Proc 2016; 48: 402-407. DOI: 10.1016/j. transproceed.2015.12.040

91. Vincent C, M.A. Miller, T.J. Edens, S. Mehrotra, K. Dewar, A.R. Manges. Bloom and bust: intestinal microbiota dynamics in response to hospital exposures and Clostridium difficile colonization or infection. Microbiome 2016; 4: 12. DOI: 10.1186/s40168-016-0156-3

92. Chang JY, D.A. Antonopoulos, A. Kalra, A. Tonelli, W.T. Khalife, T.M. Schmidt, et al. Decreased diversity of the fecal microbiome in recurrent Clostridium difficile associated diarrhea. J Infect Dis 2008; 197: 435-438.

93. Gibson GR, Roberfroid MB. Dietary modulation of the human colonic microbiota: introducing the concept of prebiotics. J Nutr 1995; 125: 1401-1412.

94. Walker AW, J. Ince, S.H. Duncan, L.M. Webster, G. Holtrop, X. Ze, et al. Dominant and diet-responsive groups of bacteria within the human colonic microbiota. ISME
$J$ 2011; 5: 220-230. DOI: 10.1038/ismej.2010.118

95. Ambalam P, M. Raman, R.K. Purama, M. Doble. Probiotics, prebiotics and colorectal cancer prevention. Best Pract Res Clin Gastroenterol 2016; 30: 119-131.

96. Araya MML, Reid G, Sanders ME, Stanton C. Guidelines for the Evaluation of Probiotics in Food. Jt. FAO/ WHOWork. Group, London, Ontario, 2002

97. Ewaschuk, J., R. Endersby, D. Thiel, H. Diaz, J. Backer, M. Ma, et al. Probiotic bacteria prevent hepatic damage and maintain colonic barrier function in a mouse model of sepsis. Hepatology 2007; 46: 841-850 10.1002/ hep. 21750

98. Hashemi A, C.R. Villa, E.M. Comelli, Probiotics in early life: a preventative and treatment approach. Food Funct 2016; 7: 1752-1768. DOI: 10.1039/c5fo01148e

99. Li D, Wang P, Hu X, Chen F. The gut microbiota: A treasure for human health. Biotechnol Adv 2016; 34:1210-1224. DOI: 10.1016/j.biotechadv.2016.08.003

100. Kang JH, Yun SI, Park HO. Effects of Lactobacillus gasseri BNR17 on body weight and adipose tissue mass in diet-induced overweight rats. $J$ Microbiol 2010; 48: 712-714. DOI: 10.1007/s12275-010-0363-8

101. Yun SI, H.O. Park, J.H. Kang, Effect of Lactobacillus gasseri BNR17 on blood glucose levels and body weight in a mouse model of type 2 diabetes. $J$ Appl Microbiol 2009; 107: 1681-1686. DOI: 10.1111/j.13652672.2009.04350.x

102. Kang JH, S.I. Yun, M.H. Park, J.H. Park, S.Y. Jeong, H.O. Park. Anti-obesity effect of Lactobacillus gasseri BNR17 in high-sucrose diet-induced obese mice. PLoS One 2013; 8: e54617. DOI: 10.1371/journal.pone.0054617

103. Liu X, Cao S, Zhang X. Modulation of gut microbiota-brain axis by probiotics, prebiotics, and diet. $J$ Agric Food Chem 2015; 63:7885-7895. DOI: 10.1021/ acs.jafc.5b02404

104. Bravo JA, P. Forsythe, M.V. Chew, E. Escaravage, H.M. Savignac, T.G. Dinan, et al. Ingestion of Lactobacillus strain regulates emotional behavior and central GABA receptor expression in a mouse via the vagus nerve. Proc Natl Acad Sci USA 2011; 108: 16050-16055. DOI: 10.1073/pnas.1102999108

105. Rao AV, A.C. Bested, T.M. Beaulne, M.A. Katzman, C. Iorio, J.M. Berardi, et al. A randomized, double-blind, placebo-controlled pilot study of a probiotic in emotional symptoms of chronic fatigue syndrome. Gut Pathog 2009; 1: 6. DOI: 10.1186/1757-4749-1-6 
105a.Sherwin E, Rea K, Dinan TG, Cryan JF. A gut (microbiome) feeling about the brain. Curr Opin Gastroenterol 2016; 32: 96-102. DOI: 10.1097/ MOG.0000000000000244

106. Wang B, Y.K. Mao, C. Diorio, M. Pasyk, R.Y. Wu, J. Bienenstock, et al. Luminal administration ex vivo of a live Lactobacillus species moderates mouse jejunal motility within minutes. FASEB J 2010; 24: 4078-4088. DOI: $10.1096 / \mathrm{fj} .09-153841$

107. Png CW, S.K. Linden, K.S. Gilshenan, E.G. Zoetendal, C.S. McSweeney, L.I. Sly, et al. Mucolytic bacteria with increased prevalence in IBD mucosa augment in vitro utilization of mucin by other bacteria. Am J Gastroenterol 2010; 105: 2420-2428. DOI: 10.1038/ajg.2010.281

108. Santacruz, A., M.C. Collado, L. Garcia-Valdes, M.T. Segura, J.A. Martin-Lagos, T. Anjos, et al. Gut microbiota composition is associated with body weight, weight gain and biochemical parameters in pregnant women. Br J Nutr 2010; 104: 83-92. DOI: 10.1017/ s0007114510000176

109. Dethlefsen L, S. Huse, M.L. Sogin, D.A. Relman. The pervasive effects of an antibiotic on the human gut microbiota, as revealed by deep $16 \mathrm{~S}$ rRNA sequencing. PLoS Biol 2008; 6: e280. DOI: 10.1371/journal.pbio.0060280

110. Goldenberg JZ, L. Lytvyn, J. Steurich, P. Parkin, S. Mahant, B.C. Johnston. Probiotics for the prevention of pediatric antibiotic-associated diarrhea. Cochrane Database Syst Rev 2015; Cd004827. DOI: 10.1002/14651858. CD004827.pub4

111. Lata J, I. Novotna, V. Pribramska, J. Jurankova, P. Fric, R. Kroupa, et al. The effect of probiotics on gut flora, level of endotoxin and Child Pugh score in cirrhotic patients: results of a double-blind randomized study. Eur J Gastroenterol Hepatol 2007; 19: 1111-1113.

112. Swidsinski A, V. Loeningae Baucke, H. Verstraelen, S. Osowska, Y. Doerffel, Biostructure of fecal microbiota in healthy subjects and patients with chronic idiopathic diarrhea. Gastroenterology 2008; 135: 568-579.

113. Kirpich IA, N.V. Solovieva, S.N. Leikhter, N.A. Shidakova, O.V. Lebedeva, P.I. Sidorov, et al. Probiotics restore bowel flora and improve liver enzymes in human alcohol-induced liver injury: a pilot study. Alcohol 2008; 42: 675-682.

114. Mastromarino P, S. Macchia, L. Meggiorini, V. Trinchieri, L. Mosca, M. Perluigi, et al. Effectiveness of Lactobacillus containing vaginal tablets in the treatment of symptomatic bacterial vaginosis. Clin Microbiol Infect 2009. 15: 67-74.

115. Roessler A, S.D. Forssten, M. Glei, A.C. Ouwehand, G. Jahreis. The effect of probiotics on faecal microbiota and genotoxic activity of faecal water in patients with atopic dermatitis: a randomized, placebo-controlled study. Clinl Nutr 2012. 31: 22-29.

116. Kajander, K., K. Hatakka, T. Poussa, M. Farkkila, R. Korpela. A probiotic mixture alleviates symptoms in irritable bowel syndrome patients: a controlled month intervention. Aliment Pharmacol Ther 2005; 22: 387394.

117. Lyra A, L. Krogius-Kurikka, J. Nikkila, E. Malinen, K. Kajander, K.S. Kurikka, et al. Effect of a multispecies probiotic supplement on quantity of irritable bowel syndrome-related intestinal microbial phylotypes. $B M C$ Gastroenterol 2010; 10: 1-9.

118. Wong VW-S., C.-H. Tse, T.T.-Y. Lam, G.L.-H. Wong, A.M.-L. Chim, W.C.-W. Chu, et al. Molecular characterization of the fecal microbiota in patients with nonalcoholic steatohepatitisâe “a longitudinal study. PloS One 2013; 8: e62885.

119. Kuehbacher, T., S.J. Ott, U. Helwig, T. Mimura, F. Rizzello, B. Kleessen, et al. Bacterial and fungal microbiota in relation to probiotic therapy (VSL\# 3) in pouchitis. Gut 2006; 55: 833-841.

120. Ng SC, E.F.C. Lam, T.T.Y. Lam, Y. Chan, W. Law, P.C.H. Tse, et al. Effect of probiotic bacteria on the intestinal microbiota in irritable bowel syndrome. J Gastroenterol Hepatol 2013; 28: 1624-1631.

121. Zhang F, W. Luo, Y. Shi, Z. Fan, G. J. Should we standardize the 1,700-year-old fecal microbiota transplantation? Am J Gastroenterol 2012; 107: 1755. DOI: 10.1038/ajg.2012.251

122. Eiseman B, W. Silen, G.S. Bascom, A.J. Kauvar. Fecal enema as an adjunct in the treatment of pseudomembranous enterocolitis. Surgery 1958; 44: 854-859.

123. Li SS, A. Zhu, V. Benes, P.I. Costea, R. Hercog, F. Hildebrand, et al. Durable coexistence of donor and recipient strains after fecal microbiota transplantation. Science 2016; 352: 586-589. DOI: 10.1126/science. aad 8852

124. Di Luccia, B., R. Crescenzo, A. Mazzoli, L. Cigliano, P. Venditti, J.-C. Walser, et al. Rescue of fructose-induced metabolic syndrome by antibiotics or faecal transplantation in a rat model of obesity. PLoS One 2015; 10: e0134893. DOI: 10.1371/journal.pone.0134893 
125. Vrieze, A., E. Van Nood, F. Holleman, J. Salojarvi, R.S. Kootte, J.F. Bartelsman, et al. Transfer of intestinal microbiota from lean donors increases insulin sensitivity in individuals with metabolic syndrome. Gastroenterology 2012; 143: 913-6.e7. DOI: 10.1053/j. gastro.2012.06.031

126. Binion DG. Strategies for management of Clostridium difficile infection in immunosuppressed patients. Gastroenterol Hepatol 2011; 7: 750-752.

127. Webb BJ, A. Brunner, C.D. Ford, M.A. Gazdik, F.B. Petersen, D. Hoda. Fecal microbiota transplantation for recurrent Clostridium difficile infection in hematopoietic stem cell transplant recipients. Transpl Infect Dis 2016; 18: 628-633 DOI: 10.1111/tid.12550

128. Kelly CR, C. Ihunnah, M. Fischer, A. Khoruts, C. Surawicz, A. Afzali, et al. Fecal microbiota transplant for treatment of Clostridium difficile infection in immunocompromised patients. Am J Gastroenterol 2014; 109: 1065-1071. DOI: 10.1038/ajg.2014.133

129. Weingarden AR, C. Chen, A. Bobr, D. Yao, Y. Lu, V.M. Nelson, et al. Microbiota transplantation restores normal fecal bile acid composition in recurrent Clostridium difficile infection. Am J Physiol Gastrointest Liver Physiol 2014; 306: G310-319. DOI: 10.1152/ajpgi.00282.2013

130. Rubin TA, C.E. Gessert, J. Aas, J.S. Bakken. Fecal microbiome transplantation for recurrent Clostridium difficile infection: report on a case series. Anaerobe 2013; 19: 22-26. DOI: 10.1016/j.anaerobe.2012.11.004

131. Brandt LJ, O.C. Aroniadis, M. Mellow, A. Kanatzar, C. Kelly, T. Park, et al. Long-term follow-up of colonoscopic fecal microbiota transplant for recurrent Clostridium difficile infection. Am J Gastroenterol 2012; 107: 1079-1087. DOI: 10.1038/ajg.2012.60

132. Di Bella, S., T. Gouliouris, N. Petrosillo. Fecal microbiota transplantation (FMT) for Clostridium difficile infection: focus on immunocompromised patients. $J$ Infect Chemother 2015; 21: 230-237. DOI: 10.1016/j. jiac.2015.01.011

133. Aas J, Gessert CE, Bakken JS. Recurrent Clostridium difficile colitis: case series involving 18 patients treated with donor stool administered via a nasogastric tube. Clin Infect Dis 2003; 36: 580-585. DOI: 10.1086/367657:

134. Youngster I, J. Sauk, C. Pindar, R.G. Wilson, J.L. Kaplan, M.B. Smith, et al. Fecal microbiota transplant for relapsing Clostridium difficile infection using a frozen inoculum from unrelated donors: a randomized, openlabel, controlled pilot study. Clin Infect Dis 2014; 58: 1515-1522. DOI: $10.1093 / \mathrm{cid} / \mathrm{ciu} 135$

135. Rossen NG, S. Fuentes, M.J. van der Spek, J.G. Tijssen, J.H. Hartman, A. Duflou, et al. Findings from a randomized controlled trial of fecal transplantation for patients with ulcerative colitis. Gastroenterology 2015; 149: 110-118. DOI: 10.1053/j.gastro.2015.03.045

136. Colman RJ, Rubin DT. Fecal microbiota transplantation as therapy for inflammatory bowel disease: a systematic review and meta-analysis. J Crohns Colitis 2014; 8: 1569-1581. DOI: 10.1016/j.crohns.2014.08.006

137. Anderson JL, Edney RJ, Whelan K. Systematic review: faecal microbiota transplantation in the management of inflammatory bowel disease. Aliment Pharmacol Ther 2012; 36: 503-516. DOI: 10.1111/j.13652036.2012.05220.x

138. Kao D, Hotte N, Gillevet P, Madsen K. Fecal microbiota transplantation inducing remission in Crohn's colitis and the associated changes in fecal microbial profile. $J$ Clin Gastroenterol 2014; 48: 625-628. DOI: 10.1097/ mcg.0000000000000131

139. Ianiro G, Bibbo S, Scaldaferri F, Gasbarrini A, Cammarota G. Fecal microbiota transplantation in inflammatory bowel disease: beyond the excitement. Medicine (Baltimore) 2014; 93: e97. DOI: 10.1097/ md.0000000000000097

140. Ni X, Fan S, Zhang Y, Wang Z, Ding L, Li Y, et al. Coordinated hospital-home fecal microbiota transplantation via percutaneous endoscopic cecostomy for recurrent steroid-dependent ulcerative colitis. Gut Liver 2016. 10: 975-980. DOI: $10.5009 /$ gnl15456

141. Grigorescu I, Dumitrascu DL. Implication of gut microbiota in diabetes mellitus and obesity. Acta Endo (Bucharest) 2016; 12: 206-214. DOI: 10.4183/aeb.2016.206

142. Costantini AV. Fungalbionics: a new concept of the etiology of gout, hyperuricemia and their related diseases. Adv Expt Med Biol 1989; 253 A: 261-268.

143. Costantini AV. The fungal etiology of gout and hyperuriceamia: The antifungal mode of action of colchicine. Biomed Rev 1992; 1: 47-52.

144 Fantuzzi G. The sound of health. Front Immunol 2014; 5:351. DOI:10.3389/fimmu.2014.00351 